Meta

Journal des tradlucteurs

Translators' Journal

\title{
A Model for Assessing Translation Quality
}

\section{Juliane House}

Volume 22, numéro 2, juin 1977

URI : https://id.erudit.org/iderudit/003140ar

DOI : https://doi.org/10.7202/003140ar

Aller au sommaire du numéro

Éditeur(s)

Les Presses de l'Université de Montréal

\section{ISSN}

0026-0452 (imprimé)

1492-1421 (numérique)

Découvrir la revue

Citer cet article

House, J. (1977). A Model for Assessing Translation Quality. Meta, 22(2),

103-109. https://doi.org/10.7202/003140ar d'utilisation que vous pouvez consulter en ligne.

https://apropos.erudit.org/fr/usagers/politique-dutilisation/ 


\section{A Model for Assessing Translation Quality*}

The essence of translation lies in the preservation of «meaning 》 across two languages. There are three aspects to this «meaning »: semantic, pragmatic, and textual such that translation may be defined as the replacement of a text in the source language by a semantically and pragmatically equivalent text in the target language. (I am concerned here only with written texts, as translation of oral texts is defined as interpretation.)

In this definition of translation the term «equivalent 》 is the key term, and the concept of equivalence is taken to be the fundamental criterion of translation quality. Thus an adequate translation text (TT) is a semantically and pragmatically equivalent one. As a first requirement for this equivalence it is posited that a translation text have a function equivalent to that of its source text (ST). Such a use of the concept of function presupposes that there are elements in any text which - given appropriate analytical tools - can reveal that text's function. Now "function 》 has been used in many different ways, e.g., in so-called «functions of language ». Various classification schemes have been devised. Most of these schemes, however, can be reduced to a basic division into a cognitive-referential (content-oriented) function and various other non-cognitive (emotive-expressive, interaction- or person-oriented) functions. The resultant two broad functional categories are useful for providing convenient labels for the two components of a text's function, which are always co-present. In the following I shall use Halliday's (1973) terms \& ideational 》 and «interpersonal for these two components.

In order to characterize the function of an individual text $I$ define function rather differently from those « functions of language », namely : the function of a text is the application or use which the text has in the context of a situation. Any text is embedded in a unique situation. From this it follows that in order to characterize the function precisely, the text must be analysed in detail. For the particular purpose of establishing functional equivalence between an ST and a TT, the ST has to be analysed first such that the equivalence which is sought for TT can be stated precisely. Since textual function was defined as the use of a text in a particular situation, each individual textual case has to be referred to the

* This paper is based on my Ph.D. thesis * A Model for Translation Quality Assessment and Some Implications for Foreign Language Teaching ", University of Toronto, 1976. An oral version of the paper was given at the BAAL Seminar of Translation, Exeter 1976. 
particular situation enveloping it. This means that a model has to be developed for determining the ST's function and the ensuing comparison of ST and TT's functions. Now, if the function of a text is to be characterized through referring the text to the enveloping situation, a way must first be found for breaking down the broad notion of «situation» into manageable parts, i.e., various situational dimensions. To do this, I use Crystal and Davy's (1969) scheme of situational dimensions - to my knowledge the most refined and elaborate scheme to date. I adapted their scheme coming up with the following set of situational dimensions :

A. Dimensions of Language User

B. Dimensions of Language Use
1. Geographical Origin

2. Social Class

3. Time

1. Medium : simple complex

2. Participation : simple complex

3. Social Role Relationship

4. Social Attitude

5. Province

The language user dimensions are fairly clear, I think; they simply relate to the text producer's geographical origin, social class, and temporal provenance. The dimensions of language use, however, need a bit more explanation. Medium may be either simple, i.e., written to be read, or complex, e.g., written to be spoken as if not written (as in a play), or simply written to be spoken (as in a draft of a speech or sermon).

Participation may also be simple or complex. Simple refers to a monologue or dialogue ; complex refers to various ways of "participation elicitation》 and indirect addressee participation in a monologue manifest linguistically e.g., in the specific use of pronouns, presence of contact parentheses, etc.

Social Role Relationship. The role relationship between addresser and addressee(s) may be symmetrical or asymmetrical according as some kind of authority relationship differentiates them. In considering the addresser's social role vis à vis the addressee(s) one needs further to distinguish the relatively permanent position role and the more transient situational role.

Social Attitude describes the degrees of social distance or proximity resulting in relative formality or informality. Joos' (1961) distinction of five different styles or degrees of formality : frozen, formal, consultative, casual, and intimate - using these in a non-rigid way, i.e., allowing for the possibility of transitional styles provide a possible schema.

The dimension of Province is a very broadly defined one : it refers not only to the text producer's occupational and professional activity but also to the field 
or topic of the text in its widest sense of « area of operation » of the language activity, as well as details of the text production as far as these can be deduced from the text itself.

Now, coming back to the earlier remarks about the function of a text, which should be kept equivalent if a translation is to be adequate, I posit that the function of a text can be determined by opening up the linguistic material in terms of this set of situational constraints. The evidence in the text which characterizes it on any one particular dimension is, of course, itself linguistic evidence. I propose to break this linguistic evidence down into three types : syntactic, lexical, textual. The situational dimensions and their linguistic correlates are then considered to be the means by which the text's function is realized, i.e., the function of a text is established as a result of an analysis of the text along the eight situational dimensions as outlined above. The basic criterion of functional match for translation equivalence can now be refined : a TT should not only match its ST in function, but employ equivalent situational-dimensional means to achieve that function, i.e., for a translation of optimal quality it is desirable to have a match between ST and TT along these dimensions which are found - in the course of the analysis to contribute in a particular way to each of the two components, ideational and interpersonal, of the text's function. By using situational dimensions for opening up the ST, a particular textual profile is obtained for the ST. This profile which characterizes the function of the text is then the norm against which the quality of the TT is to be measured, i.e., a given TT is analysed using the same dimensional scheme and in the same detail, and the degree to which its textual profile and function match or do not match ST's is the degree to which TT is more or less adequate in quality.

If a TT, in order to be adequate, had to fulfil the requirement of a dimensional, and as a result of this, a functional match, then any mismatch along the dimensions is an error. Such dimensional errors I call (by analogy with Corder's (1973) terms) covertly erroneous errors. These are differentiated from those overtly erroneous errors which result either from a mismatch of the denotative meanings of ST and TT elements or from a breach of the target language system. Overtly erroneous errors have traditionally been given more attention, whereas the kind of covertly erroneous errors which is my main aim to reveal have often been neglected as they demand a much more complex, qualitative-descriptive assessment. The relative weighting of individual errors both within the two categories and across them is a problem which varies from individual text to individual text.

The final qualitative judgment of a TT consists, then, of a listing of both covertly and overtly erroneous errors and of a statement of the relative match of the two functional components.

The notion that a mismatch on a particular situational dimension constitutes a covertly erroneous error presupposes :

1) that the socio-cultural norms or, more specifically, the norm-conditioned expectations generated by the text are essentially comparable. (In the cases of the Anglo- and Germanophone language communities relevant to the corpus of texts 
I examined this seems to have been the case.) Obvious differences in the unique cultural heritage must, of course, be stated explicitly and discussed in each particular text.

2) that the differences between the two languages are such that they can largely be overcome in translation, i.e., I assume basic intertranslatability between the two languages. Again, exceptional cases such as the non-availability of the German $d u$-Sie distinction in English must be stated explicitly and treated as exceptions. 3) that no special second function is added to TT, i.e., works translated for special purposes and for special audiences are excluded. Such translations are no longer translations but will be defined as different overt versions.

Given these three presuppositions, it is thus assumed that TT's addressees form a basically similar sub-group in the target community to the sub-group formed by the addressees of ST in the source language community, both being defined as contemporary standard language speakers. Standard language is defined as that supra-regional variety which is (commonly) used by the educated middle class speaker and which is, as an «ideal norm 》, at the same time accepted by the majority of the whole language community.

On the basis of the results of a few test cases (eight German and English textual pairs), I would now like to put forward a distinction between two types of translation : overt translation and covert translation. An overt translation is one in which the TT addressees are not being directly addressed; thus an overt translation is one which must overtly be a translation, not, as it were, a "second original». In an overt translation the ST is tied in a specific manner to the source language community and culture. However, although the ST was originally directed at source language addressees, it also points beyond the source language community, having potential general human interest. STs that call for an overt translation have an established worth or status in the source language community and potentially in other communities. Such STs may be divided into two groups :

1) overt historically-linked STs, i.e., those tied to a specific occasion in which a precisely specified source language audience is/was being addressed,

2) overt timeless STs, i.e., those transcending, as works of art and aesthetic creations, a distinct historical meaning while, of course, always necessarily displaying period and culture specificity because of the status of the addresser who is a product of his time and culture.

Both these groups of historically linked and timeless STs, then, necessitate overt translation. Now, the requirements for this type of translation lead to an important modification of the model as outlined earlier : a direct match of the original function of the ST is not possible in overt translation either because the ST is tied to a specific, non-repeatable historic event in the source culture or because of the unique status (as a literary text) that the ST has in the source culture. In cases of overt translation, a similar second level function (a topicalization of the original function) may have to be posited as a criterion for adequate translation, i.e., the one holding for the contemporary standard language speaker of the target culture and frequently also for their potential counterparts in the 
source culture who may also not be the original addressees. In overt translation, the ST as a piece of work with a certain status in the source language community has to remain as intact as possible given the process of transference into another language. On the other hand, cases of overt translation present difficulties precisely because the nature of their status in the socio-cultural context of the source language community which must be topicalized in the target culture, frequently necessitates major changes.

However, cases of overt translation are still more «straightforward $»$ as they present less subtle cultural problems than the alternative category - covert translation - to which I shall now turn.

A covert translation is a translation which enjoys or enjoyed the status of an original ST in the target culture. The translation is covert because it is not marked pragmatically as a TT of an ST but may, conceivably, have been created in its own right. A covert translation is thus a translation whose ST is not specifically addressed to a target culture audience, i.e., not tied to the source language community and culture. An ST and its covert TT are pragmatically of equal concern for source and target language addressees. Both are, as it were, equally directly addressed. An ST and its covert TT have equivalent purposes : they are based on contemporary, equivalent needs of a comparable audience in the source and target language communities. In the case of covert TTs, it is thus both possible and desirable to keep the function of ST equivalent in TT.

While these texts are thus not source-culture linked, it is the covert type of translation they require which presents more subtle cultural translation and evaluation problems. Functional equivalence is difficult to achieve whenever a wellmarked interpersonal component is discovered in the analysis of an ST calling for a covert translation. Existent and verified differences in the cultural presuppositions in the source and target language communities may then necessitate the application of a so-called cultural filter. The decision of whether the application of such a filter is necessary and justified involves at the present time, in the absence of adequate ethnological research, a subjective judgment on the part of both translator and evaluator. The unjustified application of a cultural filter leads to the production of a covert version - to be differentiated from an overt version, which, as mentioned earlier, results from the overt addition of a special secondary function to TT. A covert version in which the translator accomodated unwarrantedly and in a patterned way for the target culture group's different presuppositions about the social role relationship, social attitude, and participation of the addresser vis à vis his addressees is thus by definition an inadequate translation.

In order to clarify the distinctions between these two types of translations and versions, we may now turn to some concrete examples. An overt-historically linked ST which has the status of a document of an historical event in the source culture is exemplified by a political speech delivered by a political figure at a certain time and place addressed to a certain specified audience, or by a sermon given by a minister at a certain time, in a specific environment and directed at a certain audience. 
Overt-timeless STs are any kind of « literary » texts which have independent status in the language community through belonging to the community's cultural products.

Typical examples of STs calling for a covert translation are business circulars distributed to clients in different countries, scientific-technical texts, journalistic articles appearing in different languages in international magazines, advertisements for certain products appearing in different languages, or tourist information booklets addressed to tourists of different nationalities. In all these cases, the TT has direct addressees for whom the TT is as immediately and " originally » relevant as ST is for the source language addressees.

In a covert translation, the translator has to place a cultural filter between ST and TT, i.e., he has to, as it were, view ST through the glasses of a target culture member. In the case of the TT of a tourist information brochure, the translator may justifiably assume that the TT addressees do not necessarily share the knowledge of the source culture's inventory of cultural phenomena such as nationally well-known artists or works of art. He may then be justified in supplying added information. On the other hand, an example of an unjustified application of a cultural filter, i.e., the production of a covert version, would be the case of a commercial circular where the translator undertook changes on the dimension of Social Role Relationship in a consistent pattern such that the careful, hedging and distantly polite tone of an original English text (as evidenced in various linguistic devices) is changed, e.g., into a much more direct, blunt and undiplomatic tone in a German translation. An assumption of a German audience's different expectations is, I claim, unwarranted since it is, at present, not substantiated by facts.

Examples of overt versions are special TT editions for children with omissions, simplifications, different accentuation of certain features of ST etc.; popularizations of specialist STs designed for the lay public in the target culture ; interlingual versions or "linguistic translations 》 in which structural differences between the source and target languages are to be elucidated; résumés and abstracts.

The assumption that a particular text necessitates either a covert or an overt translation does not hold in every case. Thus, any text may, for a specific purpose, require an overt translation, i.e., it may be viewed as a document which has independent status and exists in its own right. For instance, a commercial circular might be cited as evidence in a foreign court of law, or its author may, in the course of time, prove to be a distinguished political or literary figure. Further, there may well be STs for which the choice overt-to-covert translation is a subjective one, e.g., fairy tales may be viewed as folk products of a particular culture, which would predispose a translator to opt for an overt translation, or as non-culture specific texts anonymously produced, with the general function of entertaining the young, which would suggest a covert translation; or consider the case of the Bible, which may be treated as either a collection of historical, literary documents, in which case an overt translation would seem to be called for, or as a collection of human truths directly relevant to Everyman, in which case a covert translation might seem appropriate. 
Further, it is clear that the specific purpose for which a «translation " is required will determine whether a translation or an overt version should be made. In other words, just as the decision as to whether an overt or a covert translation is appropriate for a particular text may be conditioned by factors such as the changeable status of the text producer, so clearly the initial choice between translating a given ST and producing an overt version of it, cannot be made on the basis of features of the text, but is conditioned by the arbitrarily determined purpose for which the translation/version is required.

I have distinguished a version from a translation and sought to argue a covert-overt distinction. These categories were set up in order to clarify the nature of the equivalence required for a translation of optimal quality. This equivalence is to be one of function, function being determined by a detailed opening up of a particular text as in the model I have outlined.

JULIANE House

\section{REFERENCES}

CORDER, S.P., Introducing Applied Linguistics, Harmondsworth, Penguin, 1973.

Crystat, D. and D. DAVY, Investigating English Style, London, Longman, 1969.

HALlidaY, M.A.K., Explorations in the Functions of Language, London, Arnold, 1973.

Joos, M., The Five Clocks, New York, Harcourt, Brace and World, 1961. 